Original article

\title{
Nursing students' attitudes towards coronary artery disease prevention
}

\author{
Leila Roohi Balasi', Ezzat Paryad ${ }^{2, *}$, Sara Bishiveh Moghaddam ${ }^{3}$
}

(Received: 23 June 2014; Accepted 21 Aug 2014)

\begin{abstract}
Background and Purpose: Coronary Artery Disease (CAD) is the major cause of limitation in adults' life. But it can be prevented by controlling its risk factors, modifying life style and educating the population about general health. Besides, health education is one of the important issues about changing life style. Nurses play an important role in health education . Thus this study was performed to determine Nursing Students' Attitudes towards the Prevention of Coronary Artery Disease.

Methods: The samples of this cross-sectional study have been 136 of freshman to senior nursing students of Guilan University in the north of Iran selected by available sampling method. A questionnaire consisting of two sections was used to gather data. In the first section, the samples socio-demographic data were asked and the second section with 15 questions about nursing students' attitude to coronary artery disease prevention .Data analysis was done by SPSS16 software using descriptive and inferential statistics such as Chi square, ANOVA and Pearson tests as appropriate.

Results: The findings displayed that the samples mean age was $21.34 \pm 2.52$. The majority of them were female (57.4\%) and the freshman students (36\%) and without the history of chronic disease (94.9\%) and the majority of the students and their family didn't have cardiac disease background (77.2\%). But the relationship between the score of the attitude and socio- demographic variables in the students was not significant. The finding showed that the attitude score of $48.5 \%$ students was lower than the tool's mean score but the mean score of attitude increased as the educational years increased.

Conclusion: Our findings showed that about half of the samples did not have the desired attitude towards the prevention of coronary artery disease; it is necessary to provide educational programs to create deep belief about the prevention of coronary artery disease, its importance and the students' responsibility about it.
\end{abstract}

Keywords: Attitude, Nursing students, Primary prevention, Coronary Artery Disease

\section{Introduction}

Tens of millions of patients suffer from coronary artery disease (CAD) $(1,2)$ and nowadays, this disease is a major health problem in the developing and developed countries, and not only it is a contributes to the global mortality (3-5), but also is a major cause of limitation in adults' life. In addition, $\mathrm{CAD}$ is the most common reason behind adults' hospitalization (6). Based on findings of the World Health Organization (WHO), CAD is an epidemiologic problem in the world (7) and is extremely costly for the individuals and countries that have to pay high expenses for the clients' cure and care $(2,3)$. Despite the burden on the communities, the cost of prevention behaviors is so lower than that of curing and caring $(3,8)$. The incidence of CAD is well-proportionate to its risk factors' distribution and these factors can predict CAD events(9). CAD remains a significant cause of death but it is preventable by controlling its risk factors, modifying life style and educating

\footnotetext{
${ }^{1}$ Department of Medical Surgical Nursing, Medical Educational Research Centre, Education Development Center, Guilan University of Medical Sciences, Rasht, Iran.

2,* Corresponding author: Department of Medical Surgical Nursing, Social Determinants of Health Research Center (SDHRC), Guilan University of Medical Sciences, Rasht, Iran. Email:e_paryad@GUMS.ac.ir

${ }^{3}$ MSN. Amir Almoemenin Educational Medical Center, Rasht, Iran.
} 
the population general health $(10,11)$. Controlling the risk factors can prevent $\mathrm{CAD}$ and lower the disease progress in the patients(12). The findings of many studies indicated that the majority of people need to be educated and informed about the risk factors of their illness (12-14). However, health education is one of the significant issues about change in life style (1517). Nurses play an important role in health education and the prevention of cardiovascular disease. They are an important source of information for the clients $(15,17,18)$. So all nurses have to know the principles of cardiovascular disease prevention (16). The knowledge about these principles provide the key role for nurses in order to manage the prevention of CAD $(8,14,19,20)$. As the would-be nurses, the nursing students' knowledge and attitude to CAD prevention is important (21). Nursing students attitude towards CAD prevention can have effects on their behaviors, change their behaviors and help them to educate their clients about the principles of CAD prevention $(16,21)$. Based on their attitude, nursing students can consult with their clients in the clinical setting. If care providers have positive attitude to the suitable life style role on the prevention of CAD, it can influence their clients' views(22). The findings of many studies suggested that most of the nursing students and even nurses don't have positive attitude towards the impact of life style on CAD prevention $(23,24)$, thus the detection of nursing students' attitude to CAD prevention can help to identify their ability to educate their patients about CAD prevention. So this study has been performed to determine nursing students' attitudes towards the prevention of coronary artery disease.

\section{Materials and Methods}

This study is of a cross-sectional design and Guilan University freshman to senior nursing students formed its community. The study sampling is based on the available method and 136 students completed the consent form to enter the study. A questionnaire made up of two sections was used to collect data. In the first section, the socio-demographic data of samples were asked and the second section had 15 questions about nursing students' attitude to CAD prevention with five-point Likert scale. The mean tool score was used to identify the better attitude towards CAD prevention(25). The psychometric study was not done for this tool in Iran so far; we presented it to an experts panel $(n=15)$ to detect the CVR and CVI score of this tool. A panel of 15 nursing experts expressed their views about this tool and their answers' assessment displayed that CVR and CVI scores were higher than 0.8. Alpha-Cronbach coefficient was used to determine the internal consistency of this questionnaire by a pilot study on 15 freshmen to senior nursing students. The alpha-Cronbach coefficient was 0.76 . Gathering data was done by one of the researchers via interview. Data analyzing was done by descriptive and inferential statistics such as Chi-square, ANOVA and Pearson tests in SPSS 16.

\section{Results}

This study derived finding implied that the sample's mean age was $21.34 \pm 2.52$ (ranging 18-40). The majority of them were female (57.4\%), were fresh students $(36 \%)$ and lacked the chronic disease background (94.9\%). In addition, the majority of the students and their families didn't have cardiac disease record (77.2\%). The findings showed that the attitude score of $48.5 \%$ students was lower than the mean score, but the mean score of the attitude increased as the educational years increased (Fig.1).

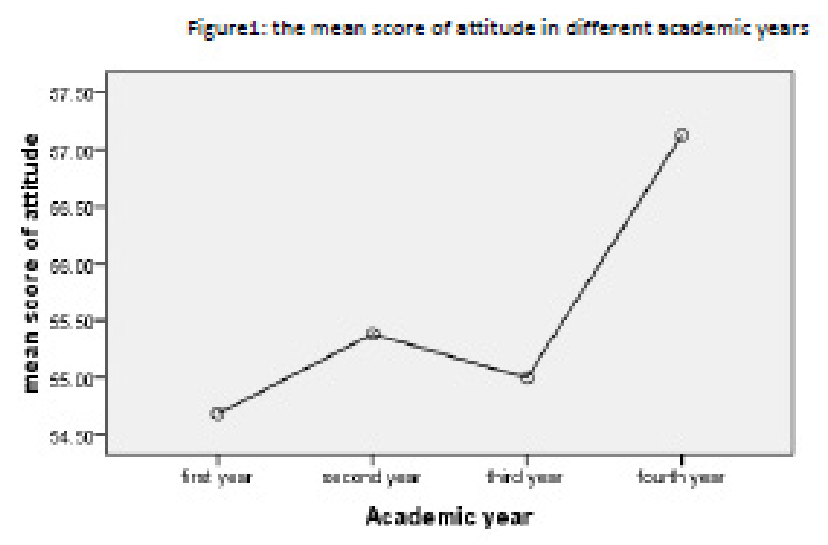


Based on ANOVA test finding, no significant difference was found in the fresh, sophomore, junior and senior students' attitude towards cardiovascular disease prevention (Table 1). To determine the relationship between the socio-demographic variables and the students' attitude to prevention, Pearson test(between age and attitude, $p=0.07), X^{2}$ test ( between the chronic disease background and attitude $\mathrm{p}=0.3$ ) and the exact Fisher test (between the educational years and attitude $\mathrm{p}=0.06 \&$ between sex and attitude $\mathrm{p}=0.08$ and between family record of heart disease and students' attitude $\mathrm{p}=0.3$ ) were used and no significant relationship existed between the score of attitude and socio- demographic variables in the students.

Table 1. relationship between the score of attitude and students' educational level

\begin{tabular}{lcccc} 
Mean score & $\begin{array}{c}\text { Negative } \\
\text { attitude }\end{array}$ & $\begin{array}{c}\text { Positive } \\
\text { attitude }\end{array}$ & Mean $\pm \mathrm{SD}^{*}$ & test \\
First year & 27 & 21 & $54.68 \pm 6.5$ & \\
Second year & 17 & 17 & $55.38 \pm 4.5$ & ANOVA \\
Third year & 15 & 21 & $55 \pm 5.5$ & $\begin{array}{c}\mathrm{F}=0.768 \\
\mathrm{P}=0.514\end{array}$ \\
Fourth year & 7 & 10 & $57.11 \pm 6.08$ & \\
\hline
\end{tabular}

* Standard Deviation

\section{Discussion}

Education, the positive effects of prevention and deep belief about the benefits and disadvantages perceived can influence the attitude towards the prevention of cardiovascular disease. Having knowledge about this issue can have effect on attitude, too. The majority of our samples were studying as the fresh students of nursing major. Maybe they haven't learned about the prevention and even CAD and its effects yet. When not enough knowledge and deep belief have been formed, the formation of positive attitude is impossible. In the first year of the nursing, not much information has been acquired by students and they haven't attended clinical settings effectively. Maybe all of the above mentioned issues can affect the majority of our samples' attitude to the positive roles of CAD prevention. Something similar to our finding was observed in the other studies, such as the one by Engler et al. (21). But it isn't similar to the findings by McFall et al. \& Wu et al. $(12,16)$. The finding by Vaida, Raj Aryal and Krettek also revealed highly satisfactory knowledge among their samples , only $14.7 \%$ had a highly satisfactory attitude towards cardiovascular health (26). Certainly different educational systems in different countries can influence the students' attitude.

Our finding implied the relationships between prevention-based attitude and demographic variable weren't significant. In the studies by McFall et al. and Murfin, the relationship between attitude towards the prevention of CAD and age and sex were not significant, either $(12,27)$. The findings of Poon and Tarrant about nursing students' attitude towards obese persons that there is a risk factor for cardiovascular disease showed no statistically significant differences in the attitudes of male and female ones (28). This finding in our study maybe related to our small sample size. In our research, the distribution of the students' sex and age didn't have homogeneity and this may have impact on these findings; because it seems that the increase in age can raise the knowledge about CAD and as a result, influence nursing students' attitude to CAD prevention.

Our finding didn't display any significant difference in the students' attitude towards the prevention of cardiovascular disease with and without chronic diseases background. But Chen, Yu \& Glaser in their study about the knowledge and attitudes of coronary heart disease prevention among the middle aged $\&$ the elderly suggested a meaningful difference between the samples' attitude with or without chronic diseases background (29). This difference between our findings may be related to our different samples' age ranges. of This study resulted finding didn't show a significant relationship between age and attitude about prevention but the study finding by Lloyd-Williams and Dogra indicated that increasing age was associated with a 
more positive view about the prevention of critical status in palliative care setting (30). All samples in this study were nursing students and at the same age and this point may have affected our findings. We didn't find statistically meaningful relationship between the attitude about prevention and family the history of heart diseases, either while the finding of Chen, Yu and Glaser about this relationship was significant (29). Our small size of samples or the type of our questionnaire might have influenced our findings.

Nursing students play a key role in health education and in this way; positive attitude about CAD prevention can help their career role. If health educators have positive attitude to prevention, it is reflected in their behaviors and then clients will believe their instruction. However, patients trust their caregivers education (16). Believing the education about prevention can help to correct the clients' wrong behavior and will be a costeffective program. The limitation in our study was the small sample size and we think if this study is done in a bigger size of the students, different findings will be achieved. In addition, studying the behavior inside the attitude can help make better planning for health education in society and clinical setting.

\section{Conclusion}

Based on our findings that showed about half of the samples did not have the desired attitude towards the prevention of coronary artery disease; it is necessary to provide educational programs. These educational programs must create a deep belief about coronary artery disease prevention, its importance and students' responsibility about it.

\section{Conflict of interests}

The authors declared that they had no competing interests.

\section{Author's contributions}

L.Rouhi Balasi was responsible for the study design and performed data collection and data analysis. E.Paryad was responsible for study conception and design and design and draft of the manuscript and supervision of the study. S.Bishiveh Moghaddam performed data collection and data analysis.

\section{Acknowledgment}

We sincerely appreciate the students who took part in the study and the Research Committee of Nursing $\&$ Midwifery Faculty of Guilan University of Medical Sciences.

\section{References}

1. BG Bare, JL Hinkle, KH Cheever, Smeltzer C. Brunner \& Suddarths Textbook of medical-surgical nursing .11th ed. Philadelphia: Lippincott Williams \& Wilkins; 2010.

2. Mohammad Hassani MR, Farahani B, Zohour AR, Panaei Azar SH. Self-care ability based on Orem's theory in the individuals with Coronary Artery Disease (CAD). IJCCN. 2010; 3(2): 87-91(Persian).

3. Seyam SH, Hidarnia AR, Tavafian SS. Self-care education through coping style for patients after heart surgery. Journal of Isfahan Medical School. 2011; 29(135): 432-444(Persian).

4. Sarraf-Zadegan N, Sadri G, Malek Afzali H, Baghaei M, Mohammadi Fard N, Shahrokhi S, et al. Isfahan healthy heart program: a comprehensive integrated community-based program for cardiovascular disease prevention and control. Design,methods and initial experience. Acta cardiol. 2003; 58(4): 309320 .

5. Rabiei K, Kelishadi R, Sarrafzadegan N, Abedi HA, Alavi M, Heidari K, et al. Process evaluation of a community-based program for prevention and control of non-communicable disease in a developing country. BMC Public Health. 2009; 9(1): 57.

6. Seyam SH, Heidaryan AR, Tavafian SS. Self-caring behaviors among cardiac patients after coronary artery bypass graft surgery. Journal of Guilan university of medical sciences. 2011; 20(79): 31-39 (Persian).

7. Allen LaPointe NM, Ou FS, Calvert SB, Melloni C, 
Stafford JA, Harding T, et al. Association between patient's beliefs and medication adherence following hospitalization for acute coronary syndrome. Am Heart J. 2011; 161(5): 855-863.

8. Sadeghi Sherme M,Razmjooei N, Ebadi A, Najafi Mehri S, Asadi-Lari M, Bozorgzad P. Effect of applying continuous care model on quality of life of patients after coronary artery bypass graft. IJCCN. 2009; 2(1): 1-6 (presian).

9. Gholipour M, Tabrizi A. Prevalence of cardiovascular risk factors among students of Sharif University of Technology Students. Cardiovascular Nursing Journal. 2012; 1(2): 48-56 (Persian).

10. Byrne M, Walsh J, Murphy AW. Secondary prevention of coronary heart disease: patient beliefs and healthrelated behaviour. J psychosom Res. 2005; 58(5): 403-415.

11. Azizi F, Ghanbarian A, Momenan AA, Hadaegh F, Mirmiran P, Hedayati M, et al. Prevention of noncommunicable disease in a population in nutrition transition: Tehran Lipid and Glucose Study phase II. Trials. 2009; 10(1): 5 .

12. McFall, Nonneman R, Rogers LQ, Mukerji V. Health care student attitudes towards the prevention of cardiovascular disease. Nurs Educ Perspect. 2009; 30(5): 285-289.

13. Eshah NF, Bond AE, Froelicher ES. The effects of a cardiovascular disease prevention program on knowledge and adoption of a heart healthy lifestyle in Jordanian working adults. Eur J Cardiovasc Nurs. 2010; 9(4): 244-253.

14. Voogdt-Pruis HR, Beusmans GH, Gorgels AP, van Ree JW. Experiences of doctors and nurses implementing nurse-delivered cardiovascular prevention in primary care: a qualitative study. J Adv Nurs. 2011; 67(8): 1758-1766.

15. Nagle A, Schofield M, Redman S. Australian nurses' smoking behaviour, knowledge and attitude towards providing smoking cessation care to their patients. Health Promot Int. 1999; 14(2): 133-144.

16. Wu Y, Deng Y, Zhang Y. Knowledge, attitudes, and behaviors of nursing professionals and students in Beijing toward cardiovascular disease risk reduction. Res Nurs Health. 2011; 34(3): 228-240.

17. Kofi JO. Prevention \& management of hypertension: a study on knowledge and attitudes of women of childbearing age. (Thesis). Ostrobothnia: Central Ostrobothnia University of Applied Scinces; 2011.

18. Millman FK. Factors associated with nurses' practice intentions to provide heart disease risk \& prevetion -based education to women patinets. ( $\mathrm{PhD}$ Thesis). Health and Medical Sciences: New Jersey: Seton Hall University; 2011.

19. Harris M. The role of primary health care in preventing the onset of chronic disease, with a particular focus on the lifestyle risk factors of obesity, tobacco and alcohol. UNSW. Canberra: National Preventative Health Taskforce. Australian National Preventive Health Agency; 2008.

20. Ai-Dharrab SA, Mangoud AM, Mohsen MF. Knowledge, attitude and practice (KAP) of primary health care physicians and nurses towards hypertension: a study from Dammam, Saudi Arabia. J Family Community Med. 1996; 3(2): 57-63.

21. Engler MM, Engler MB, Davidson DM, Slaughter RE. Cardiovascular disease prevention: Knowledge and attitudes of graduate nursing students. J Adv Nurs. 1992; 17(10): 1220-1225.

22. Steptoe A, Doherty S, Kendrick T, Rink E, Hilton S. Attitudes to cardiovascular health promotion among GPs and practice nurses. Fam Pract. 1999; 16(2): 158-163.

23. Brown I. Nurses' attitudes towards adult patients who are obese: literature review. J Adv nurs. 2006; 53(2): 221-232.

24. Tabiei Sh, Saadatjoo SA, Hoseinian SZ, Naseri MS, Eisanejad L, Ghotbi M, et al. Nurses` knowledge and attitude towards care delivery to the aged with cardiovascular diseases. Modern Care J. Scientific Quarterly of Birjand Nursing and Midwifery Faculty. 2011; 7(3,4): 41-47(Persian).

25. Greenland P, Castle CH, Cohen JD, Davidson DM, 
Krakoff LR, Nowacek GA, et al. Attitude towards prevention of cardiovascular disease among first year students at eight American medical schools, 1983-1985. Prev Med. 1988; 17(6): 700-711.

26. Vaidya A, Aryal UR, Krettek A. Cardiovascular health knowledge, attitude and practice/behaviour in an urbanising community of Nepal: a populationbased cross-sectional study from Jhaukhel-Duwakot Health Demographic Surveillance Site. BMJ Open. 2013; 3(10): e002976.

27. Murfin R. Coronary heart disease knowledge and health behaviour in student nurses.(Thesis). Chester:
University of Chester ; 2010.

28. Poon MY, Tarrant M. Obesity: attitudes of undergraduate student nurses and registered nurses. J Clin Nurs. 2009; 18(16): 2355-2365.

29. Chen W Ch, Yu Y Ch, Glaser K. The knowledge and attitudes of coronary heart disease prevention among middle and older aged people in a community in Taipei. Taiwan Geriatr Gerontol. 2009; 4(4): 251-262.

30. Lloyd-Williams M, Dogra N. Attitudes of preclinical medical students towards caring for chronically ill and dying patients: does palliative care teaching make a difference? Postgrad Med J. 2004; 80(939): 31-34. 